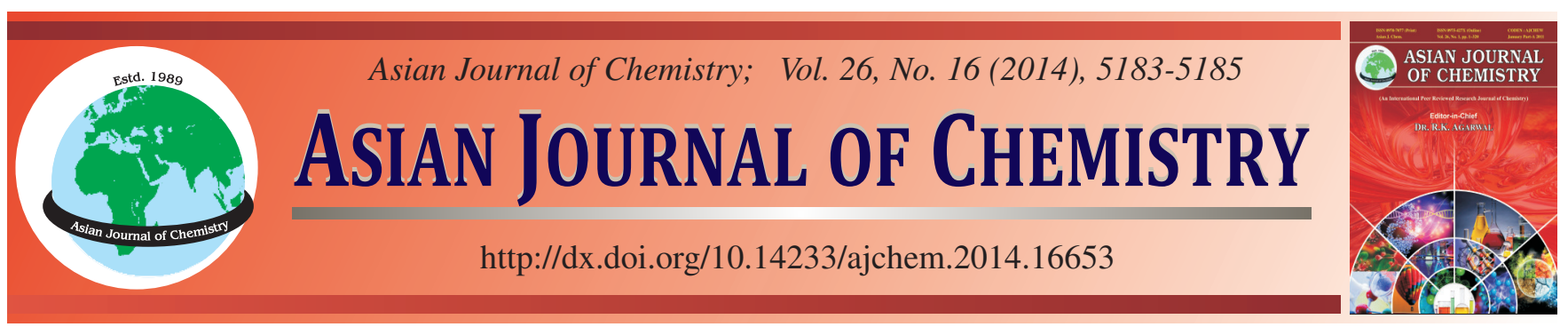

\title{
Antimicrobial Evaluation and Crystal Structure of Parthenolide from Tarconanthus camphoratus Collected in Saudi Arabia
}

\author{
Wadah Jamal ${ }^{1}$, Ahmed Bari ${ }^{2, *}$, Ramzi A. Mothana ${ }^{3}$, Omer Basudan ${ }^{3}$, Mona S. Mohammed ${ }^{1}$ and S.W. NG ${ }^{4}$
}

\author{
${ }^{1}$ Department of Pharmacognosy, University of Khartoum, P.O. Box 321, Khartoum, Sudan \\ ${ }^{2}$ Department of Pharmaceutical Chemistry, College of Pharmacy, King Saud University, P.O. Box 2457, Riyadh, 11451, Saudi Arabia \\ ${ }^{3}$ Department of Pharmacognosy, College of Pharmacy, King Saud University, P.O. Box 2457, Riyadh, 11451, Saudi Arabia \\ ${ }^{4}$ Department of Chemistry, University of Malaya, 50603 Kuala Lumpur, Malaysia
}

*Corresponding author: Tel: +966 533977946, Fax: +966 14676220; E-mail: abari@ksu.edu.sa

Tarconanthus camphoratus is a perennial traditional medicinal herb and is a rich source of sesquiterpene lactones called parthenolides. 4xi-Germacra-1(10)-11(13)-dien-12-oic-acid-4,5-epoxy-6 $\alpha$-hydroxy- $\gamma$-lactone (parthenolide) contains both an $\alpha$-methylene- $\gamma$-lactone ring and an epoxide group, which interact with the nucleophilic sites of many biological molecules. Here in, we reported the crystal structure in vitro antimicrobial activities and MIC evaluation of parthenolide isolated from Saudi Arabian plant.

Keywords: Parthenolide, Anti-microbial, Sesquiterpene lactone, Anti-inflammatery, Asteraceae.

\section{INTRODUCTION}

Tarchonanthus camphoratus is an aromatic dioecious shrub; the leaves are alternate, shortly petiolate, and lanceolate to narrowly elliptic, entire, grey-green above and whitetomentose below. The plant grows in southern regions of Saudi Arabia and Yemen. It is the only plant belonging to the genus Tarconanthus which found in the two countries. The folkloric use of Tarchonanthus camphoratus in southern Saudi Arabia is limited. The plant is used as a source of light in the form of torches and as incense sticks. The plant also grows spontaneously on the high plateaus of eastern, sub-tropical and semiarid regions of Africa, as well as in South Africa. In Yemen it is used for the treatment of wounds and urinary tract infections while as in South Africa it is used to relieve toothache to treat respiratory problems and as a source of volatile oils in perfumery.

In recent years, researchers have developed interest in plants with antimicrobial properties since multiple drug resistance in bacteria has emerged due to in appropriate use of antimicrobial drugs ${ }^{1}$. This increasing number in multiple drug resistant bacteria demands new antimicrobial compounds from various sources such as medicinal plants. Thus, the search for herbal extracts may offer a unique potential for the development of novel agents to treat infections ${ }^{2}$. Tarchonanthus camphoratus was used as anti-inflammatory in previous years and has also attracted attention because of its potential to treat migraine and cancer cells. Parthenolide (Fig. 1) is a sesquiterpene lactone derived from this plant which has been used in folk medicine for anti-inflammatory activity ${ }^{3}$. Current paper is focused on parthenolide as an antimicrobial agent. Members of family Asteraceae which display several kinds of biological activities have been used for medicinal purposes for many years ${ }^{4}$. The large number of sesquiterpenoids and sesquiterpene that are typical constituents of these plants might be responsible for these effects. Sesquiterpene lactones are major class of terpenoids, particularly abundant in Asterceae family and play key role in chemical defense for plants against pathogens ${ }^{5-7}$. Tarchonanthus camphoratus has not previously been the subject of a phytochemical investigation and four known sesquiterpenes were isolated from $T$. camphoratus growing in Saudi Arabia ${ }^{8-10}$. These sesquiterpenes were identified as costunolide, isocostic acid, 3 $\beta$-hydroxy-1,2 dehydrocostic acid and parthenolides ${ }^{11}$. Various flavones, luteolin, apigenin, nepetin and hispidulin have been identified in Egyptian collections of this species, as well as a quaternary alkaloid, tarchonanthine ${ }^{12}$. Parthenolide and its biological activities have been published in literature but the crystal structure has never been reported. This compound is isolated for the first time from this plant, and no evidence could be found for the previous reported presence of parthenolide in the genus Tarconanthus. In this publication we report the first crystal structure of 4xiGermacra-1(10)-11(13)-dien-12-oic-acid-4,5-epoxy-6 $\alpha$-hydroxy$\gamma$-lactone isolated from the hexane extract of $T$. camphorates 


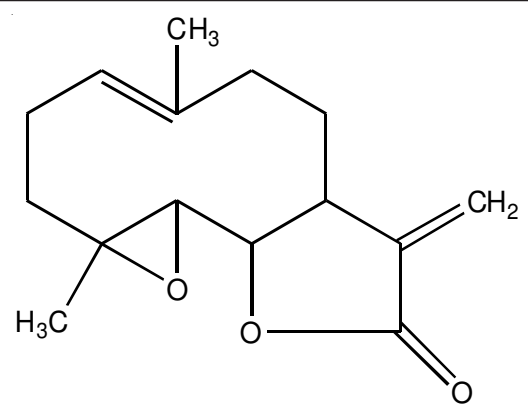

Fig. 1. Structure of parthenolide

and its antimicrobial activity. The product was recrystallized by slow evaporation in hexane-ethylacetate mixture to get the crystals.

\section{EXPERIMENTAL}

The leaves of Tarconanthus camphorates were collected from the southern region of Saudi Arabia and a voucher specimen was deposited in the Herbarium of the College of Pharmacy, King Saud University, Riyadh, Saudi Arabia.

Method: $150 \mathrm{~g}$ of the air-dried and powdered leaves of $T$. camphoratus was exhaustively extracted with $n$-hexane using a soxhlet apparatus. The extract was concentrated under reduced pressure using rotary evaporator where $18 \mathrm{~g}$ of the hexane extract was obtained. This hexane extract was subjected to silica gel column chromatography using petroleum etherethyl acetate as gradient of increasing polarity to give 15 fractions (1 to 15). Fraction 9 ( $1 \mathrm{~g}$ ) was chromatographed over silica gel (hexane-ethylacetate) as gradient of increasing polarity to give, after preparative TLC purification (DCM$\mathrm{MeOH}, 90: 10)$, parthenolides (0.04 g).

The structure of the isolated compound was identified by nuclear magnetic resonance (NMR; Bruker), ${ }^{1} \mathrm{H}$ NMR (500.133 MHz) and ${ }^{13} \mathrm{C} \mathrm{NMR}(125.75 \mathrm{MHz})$ analyses in $\mathrm{CDCl}_{3}$ with TMS as internal standard. Infrared analysis (Perkin Elmer spectrum BX FT-IR spectrometer) and mass mass spectra were carried out on a Jeol JMS-700 mass spectrometer. Chromatographic data of a sesquiterpene parthenolides is in accordance with the literature data ${ }^{13}$.

Antimicrobial screening: Parthenolide was screened for their in vitro growth inhibitory activity. For antifungal test, Candida albicans ATCC 2091 were chosen. Amphotericin B was used for comparison. The bacterial strains used were Staphylococcus aureus ATCC 6538P, Bacillus subtilis ATCC 6633 and Mycobacterium smegmatis ATCC 14468 (all Grampositive) and Ecsherichia coli ATCC 25922 and Pseudomonas aeruginosa MTCC 741 (all Gram-negative). The plates were incubated at $33{ }^{\circ} \mathrm{C}$ for 24 and $48 \mathrm{~h}$, respectively for bacteria and fungi. The inhibition zones of microbial growth were measured by paper disc method ${ }^{14}$ in which paper disc of $8 \mathrm{~mm}$ containing specified amount of synthesized compounds were placed on an agar plate inoculated with a standardized suspension of the microorganisms tested. Ciprofloxacin for Grampositive bacteria, naldixic acid for Gram-negative bacteria and amphotericin B for fungi was used as standards. The experiments were carried out three times and the inhibition zones produced by various synthesized compounds were measured in millimeters (diameter in $\mathrm{mm}$ ). The results of antibacterial activities of parthenolide against different microbes are summarized in Table-1. It has been observed that the parthenolide exhibits interesting antibacterial activities.

TABLE-1

ANTIMICROBIAL EVALUATION OF PARTHENOLIDE

\begin{tabular}{ccc} 
Organisms tested & MIC values & Zone inhibition \\
\hline Bacillus subtilis & MIC $=25 \mu \mathrm{g} / \mathrm{mL}$ & 8.5 \\
Staphylococcus aureus & MIC $=25 \mu \mathrm{g} / \mathrm{mL}$ & 9.25 \\
Escherichia coli & $-\mathrm{ve}$ at $1 \mathrm{mg} / \mathrm{mL}$ & - \\
cedomonas aeruginosa & $-\mathrm{ve}$ at $1 \mathrm{mg} / \mathrm{mL}$ & - \\
Candida albicans & -ve at $1 \mathrm{mg} / \mathrm{mL}$ & - \\
MIC $=300 \mu \mathrm{g} / \mathrm{mL}$ & 11.40
\end{tabular}

${ }^{*} \mathrm{MIC}=$ minimum inhibitory concentration; "Zone inhibition in milli meter (mm); "Sample was tested first at $1 \mathrm{mg} / \mathrm{ml}$ if it is positive, then MIC will be determined; ${ }^{(D M S O)}$ was used as solvent

Minimal inhibitory concentration (MIC) determination: Microdilution method was followed for determination of MIC values. Parthenolide was resuspended in DMSO to make 1 $\mathrm{mg} / \mathrm{mL}$ final concentration and then was added to broth media of 96-wells of microtiter plates using two fold serial dilutions. $100 \mu \mathrm{L}$ inoculum was then added to each well. Bacterial suspensions were used as negative control, while broth containing standard drug was used as positive control. The respective antibiotics were chosen because they are often employed as first line antibiotics in the respective bacterial infections. The microtiter plates were incubated at $37^{\circ} \mathrm{C}$ for $24 \mathrm{~h}$ for bacteria, $27^{\circ} \mathrm{C}$ for $48 \mathrm{~h}$ for yeast and $27^{\circ} \mathrm{C}$ for 5 days for fungi. At least three repetitions were run for each assay and each time two sets of microtiter plates were prepared, one was kept for incubation while another set was kept at $4{ }^{\circ} \mathrm{C}$ for comparing the turbidity in the wells of microtiter plate. MIC (Table-1) was determined to be where growth was no longer visible. The turbidity of the wells in the microtiter plate was interpreted as visible growth of microorganisms. Strong activity was defined as MIC $>1 \mathrm{mg} / \mathrm{mL}$.

X-Ray crystallographic study of compound: Crystals of parthenolide was obtained by crystallization from a 4:1 hexane-ethylacetate solution by allowing slow solvent evaporation. X-Ray structure determination was performed on Agilent Technologies SuperNova Dual diffractometer with Atlas detector SuperNova (Mo) X-ray source. The crystal structure appears to be a dimer (Fig. 2) and was solved by the Patterson heavy atom method and successive cycles of full matrix refinement and Fourier difference syntheses. All nonhydrogen atoms were refined anisotropically by full matrix least squares. Carbon-bound $\mathrm{H}$-atoms were placed in calculated positions [C-H 0.95 to $0.98 \AA$, $\mathrm{U}_{\text {iso }}(\mathrm{H}) 1.2$ to $1.5 \mathrm{U}_{\text {eq }}(\mathrm{C})$ ] and were included in the refinement in the riding model approximation Table-2. Molecular graphics were performed from X-SEED. Crystallographic data for the structure reported in this paper have been deposited with the Cambridge Crystallographic Data Centre as supplementary publication no. CCDC: 918225 . Copies of the data can be obtained free of charge on application to CCDC, 12 Union Road, Cambridge CB2 1EZ, UK (Fax: +44 1223 336033, E-mail: deposit@ccdc.cam.ac.uk or http://www.ccdc.cam.ac.uk). 


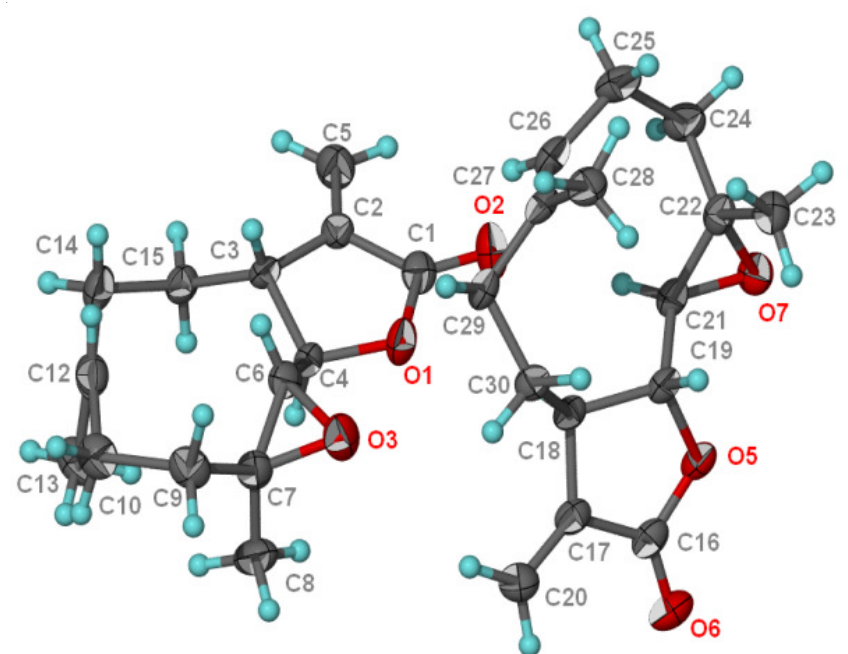

Fig. 2. Labelled ORTEP diagram of parthenolide with $50 \%$ thermal probability ellipsoids

\begin{tabular}{|c|c|}
\hline \multicolumn{2}{|c|}{$\begin{array}{c}\text { TABLE-2 } \\
\text { CRYSTALLOGRAPHIC DATA }\end{array}$} \\
\hline \multicolumn{2}{|l|}{ Crystal data } \\
\hline Chemical formula & $\mathrm{C}_{15} \mathrm{H}_{20} \mathrm{O}_{3}$ \\
\hline $\mathrm{M}_{\mathrm{r}}$ & 248.31 \\
\hline Crystal system, space group & Orthorhombic, $\mathrm{P} 2{ }_{1} 2_{1} 2_{1}$ \\
\hline Temperature $(\mathrm{K})$ & 100 \\
\hline a, b, c $(\AA)$ & $11.8177(7), 11.9875(6), 18.8455(11)$ \\
\hline $\mathrm{V}\left(\AA^{3}\right)$ & $2669.7(3)$ \\
\hline $\mathrm{Z}$ & 8 \\
\hline Radiation type & $\operatorname{MoK}_{\alpha}$ \\
\hline$\mu\left(\mathrm{mm}^{-1}\right)$ & 0.09 \\
\hline Crystal size (mm) & $0.30 \times 0.30 \times 0.05$ \\
\hline Diffractometer & $\begin{array}{l}\text { Agilent Technologies Super Nova Dual } \\
\text { diffractometer with Atlas detector }\end{array}$ \\
\hline Absorption correction & $\begin{array}{l}\text { Multi-scan } \\
\text { CrysAlis PRO (Agilent, 2012) }\end{array}$ \\
\hline $\mathrm{T}_{\min }, \mathrm{T}_{\max }$ & $0.975,0.996$ \\
\hline $\begin{array}{l}\text { No. of measured, independent and } \\
\text { observed }[\mathrm{I}>2 \sigma(\mathrm{I})] \text { reflections }\end{array}$ & $14549,3457,2946$ \\
\hline $\mathrm{R}_{\text {int }}$ & 0.044 \\
\hline$(\sin \theta / \lambda)_{\max }\left(\AA^{-1}\right)$ & 0.651 \\
\hline $\mathrm{R}\left[\mathrm{F}^{2}>2 \sigma\left(\mathrm{F}^{2}\right)\right], \mathrm{wR}\left(\mathrm{F}^{2}\right), \mathrm{S}$ & $0.041,0.103,1.04$ \\
\hline No. of reflections & 3457 \\
\hline No. of parameters & 327 \\
\hline No. of restraints & 0 \\
\hline $\mathrm{H}$-atom treatment & $\mathrm{H}$-atom parameters constrained \\
\hline$\Delta \rho_{\max }, \Delta \rho_{\min }\left(\mathrm{e} \AA^{-3}\right)$ & $0.21,-0.17$ \\
\hline
\end{tabular}

\section{ACKNOWLEDGEMENTS}

The authors extended their appreciation to the Deanship of Scientific Research at King Saud University for funding the work through the research group project No. (RGP-VPP073).

\section{REFERENCES}

1. A.M. Brown, C.M. Edwards, M.R. Davey, J.B. Power and K.C. Lowe, J. Pharm. Pharmacol., 49, 558 (1997).

2. S.P. Hehner, T.G. Hofmann, W. Dröge and M.L. Schmitz, J. Immunol., 163, 5617 (1999).

3. D.W. Knight, Nat. Prod. Rep., 12, 271 (1995).

4. B.H. Kwok, B. Koh, M.I. Ndubuisi, M. Elofsson and C.M. Crews, Chem. Biol., 8, 759 (2001).

5. H. Nakshatri, S.E. Rice and P. Bhat-Nakshatri, Oncogene, 23, 7330 (2004).

6. J.J. Ross, J.T. Arnason and H.C. Birnboim, Planta Med., 65, 126 (1999).

7. J. Wen, K.R. You, S.Y. Lee, C.H. Song and D.G. Kim, J. Biol. Chem., 277, 38954 (2002).

8. J.M. Woynarowski and J. Konopa, Mol. Pharmacol., 19, 97 (1981).

9. Q. Zhang, Y. Lu, Y. Ding, J. Zhai, Q. Ji, W. Ma, M. Yang, H. Fan, J. Long, Z. Tong, Y. Shi, Y. Jia, B. Han, W. Zhang, C. Qiu, X. Ma, Q. Li, Q. Shi, H. Zhang, D. Li, J. Zhang, J. Lin, L.-Y. Li, Y. Gao and Y. Chen, J. Med. Chem., 55, 8757 (2012).

10. S. Collenette, An Illustrated Guide to the Flowers of Saudi Arabia; Scorpion: London, p. 283 (1985).

11. M.A. Al-Yahya, I.A. Al-Meshal, J.S. Mossa, A.A. Al-Badr and M. Tariq, Saudi Plants: A Phytochemical and Biological Approach; King Abdul Aziz City for Science \& Technology (KACST): Riyadh, pp. 32-34 (1990).

12. M. Majdi, Q. Liu, G. Karimzadeh, M.A. Malboobi, J. Beekwilder, K. Cankar, R. Vos, S. Todorovic, A. Simonovic and H. Bouwmeester, Phytochemistry, 72, 1739 (2011).

13. D.V.C. Awang, B.A. Dawson, D.G. Kindack, C.W. Crompton and S. Heptinstall, J. Nat. Prod., 54, 1516 (1991).

14. Y.L. Nene and P.N. Thapliyal, Fungicides in Plant Disease Control, IBH, New Delhi, India (1982). 